\title{
Propuestas y hallazgos preliminares para un análisis sobre mujeres ejecutivas en la Ciudad de México
}

\author{
Guadalupe Serna
}

\begin{abstract}
El presente artículo pone a discusión los primeros hallazgos que el trabajo de campo reporta sobre la trayectoria familiar, educativa y laboral, de un pequeño grupo de mujeres que se desempeñan en puestos de dirección en grandes empresas de la ciudad de México. El propósito es contribuir al conocimiento de un grupo de actores económicos, que en el caso de nuestro país ha sido poco analizado: las ejecutivas de alto nivel. En este primer acercamiento discuto cuáles han sido algunas de las preocupaciones y hallazgos que se han hecho sobre estos nuevos actores globales que son ahora muy comunes en las grandes ciudades. Propongo una definición que me ha resultado útil para emprender este análisis y que, sin embargo, es susceptible de modificarse en la medida en que se avance en el análisis. Al acercarme a estos actores económicos me ocupo de sus características generales, mediante el análisis de sus trayectorias intento plasmar cómo se enfilan hacia lo que será su carrera en el mundo corporativo. Los problemas que estas mujeres enfrentan en su ruta de ascenso y cómo perciben los límites hasta donde pueden llegar.
\end{abstract}

This article discusses the initial findings reported from field work on the family, the educational and work trajectory of a small group of women employed in management positions in large companies in Mexico City. The aim is to contribute to the knowledge on a group of economic actors that, in the case of Mexico, has been scarcely analyzed: high-level executives. In this first approach I discuss some of the concerns and findings made on these new global actors who are now very common in large cities. I propose a definition which has been useful to me in carrying out this analysis but which, however, is susceptible to being modified during the course of the analysis. When approaching these economic actors I concern myself with their general characteristics and, by analyzing their trajectories, seek to grasp how they proceed towards a career in the corporate world; the problems these women face on their way up and their perception of the limits of how far they can go.

GUADALUPE SERnA: Instituto de Investigaciones Dr. José María Luis Mora.

Desacatos, núm. 11, primavera 2003, pp. 77-96.

* El presente ensayo discute parte de la información derivada del proyecto "Mujeres ejecutivas en México: una incursión distinta de la mujer en la actividad laboral en una época de globalización", financiado por Conacyt. 


\section{INTRODUCCIÓN}

$\mathrm{V}$

isten elegantes trajes obscuros confeccionados en seda a la medida por algún sastre en Hong Kong y se acompañan de un portafolio de prestigiada marca. Viajan por todo el mundo, especialmente hacia las ciudades de carácter mundial como Nueva York, Londres o Tokio y en menor medida a algunas grandes ciudades latinoamericanas. Suelen comer en restaurantes donde chefs, de reconocido prestigio internacional, preparan platillos de nouvelle couisine. Son mujeres altas, delgadas, generalmente de tez blanca, trabajan en modernos edificios de cristal, muchos de ellos inteligentes, en un ambiente sofisticado y de buenas maneras son: mujeres ejecutivas.

Ésta es la imagen más común que las revistas y los medios de comunicación visual e impresos ofrecen de las mujeres que se desempeñan como ejecutivas en las grandes empresas y corporaciones multinacionales. Elemento que alude, fundamentalmente, a un estereotipo que poco nos informa acerca de estas mujeres como actores económicos e integrantes de la sociedad actual. ¿¿Cuánto de erróneo y confuso hay en estas imágenes? ¿Quiénes son estas mujeres? ¿Qué trayectoria personal y educativa tienen? ¿Cómo y cuáles son las rutas que han seguido al insertarse en un mundo del trabajo? ¿Qué tipo de habilidades se requiere para desempeñarse como ejecutiva? ¿Qué significa ser ejecutiva y cómo se definen?

Éstas son algunas de las preocupaciones que han guiado la presente investigación en donde el objetivo principal es indagar acerca de las trayectorias educativas y laborales de un grupo de mujeres ejecutivas que trabajan en empresas nacionales y de carácter multinacional asentadas en la Ciudad de México. ${ }^{1}$ Me interesa analizar parte del material que he recopilado a lo largo una temporada de trabajo de campo, así como materiales secundarios que considero me permiten dar respuesta a algunas de las interrogantes planteadas.

${ }^{1}$ Cuando me refiero a la Ciudad de México incluyo a las 16 delegaciones la zona conurbada así como algunos municipios del Estado de México, ya que varias de las entrevistadas viven e incluso trabajan en la zona conurbada. No obstante, la información de carácter censal solamente se refiere al Distrito Federal.
Una de las primeras preocupaciones fue consultar cómo se ha abordado el estudio de las mujeres ejecutivas en la bibliografía sobre el tema, cuáles han sido las preocupaciones alrededor de este tema y qué hallazgos se han reportado, seguido de intentar determinar estadísticamente qué proporción guarda este sector dentro del grupo femenino que participa en el mercado laboral, para finalmente centrarme, a partir de la información empírica recopilada, en las características que tienen estas mujeres y cuáles son las rutas que han seguido para incorporarse al mundo ejecutivo. El propósito es develar esa imagen de "glamour y éxito" asociado a este grupo y mostrar lo que en sus propias palabras son: mujeres trabajadoras profesionales que se desempeñan en un competido mundo corporativo masculino.

\section{LA IMPORTANCIA DEL OBJETO DE ESTUDIO Y SU DEFINICIÓN}

Desde la década de los setenta se registró un incremento en la participación económica femenina en países como Estados Unidos, el Reino Unido y Europa Occidental y lo mismo sucedió para el caso de México. El origen de este suceso estuvo sin duda ligado a la expansión de la industria de servicios. Esto trajo aparejado un cambio en el papel de las mujeres en la sociedad que permitió un participación activa en la actividad económica, tanto en empleos de tipo independiente, vía la formación de sus propias empresas, como en empleos que requerían de calificaciones profesionales, que sería el caso de las mujeres con cargos ejecutivos y aún, en empleos poco calificados en donde era poco probable que se obtuviera una promoción o una posición de mayor responsabilidad.

En Estados Unidos, para mediados de los ochenta, la participación de la mujer en la actividad laboral era del $45 \%$, en tanto que para el Reino Unido, en 1989 el porcentaje era del $44 \%$. Para el mismo año, en la mayor parte de los países de Europa Occidental, más de la tercera parte de la fuerza de trabajo eran mujeres. Dentro de este grupo Dinamarca tenía el porcentaje más alto con un $45 \%$ de participación femenina. Patrones un tanto diferentes mostraban países como Australia, con un $37 \%$ y 


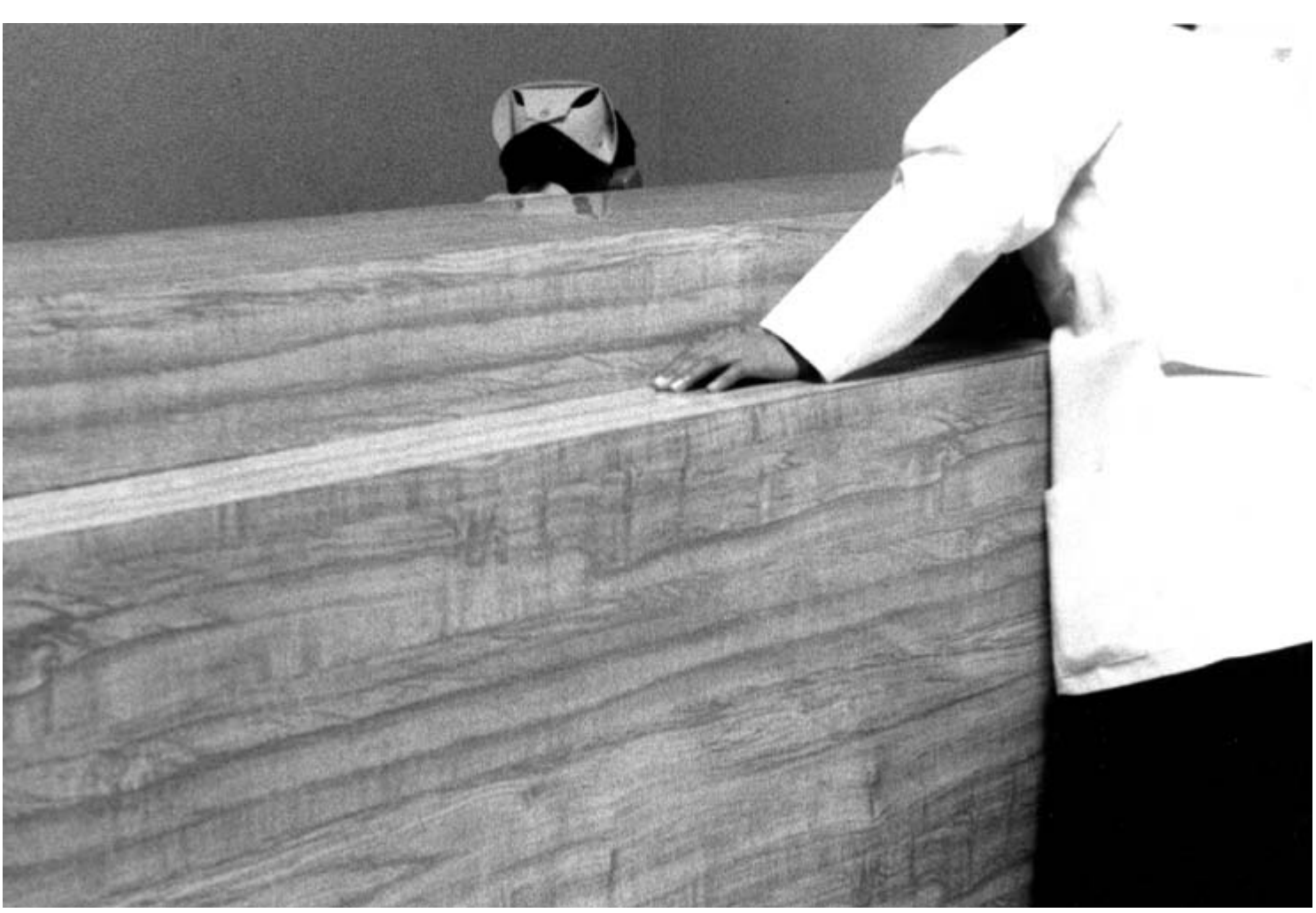

De la serie: Alto, mujeres trabajando, 2003 / Roxana Acevedo

Nueva Zelanda con un 38\% para el mismo año (Davidson y Cooper, 1992). Para el caso de México las tasas de participación femenina pasaron del 16\% en 1970, al 30\% en 1990, sin duda menor a las que se registraban en países industrializados. No obstante, el incremento continuó en ascenso y para el año 2000 la población económicamente activa femenina representó el $39 \%$. Esto por lo que hace a la participación económica femenina en general.

Por otra parte, los estudios centrados en la participación femenina en actividades gerenciales reportan que en las últimas dos décadas, se registró un incremento en su participación en puestos gerenciales y directivos en empresas y corporaciones, generalmente compuestos por población masculina. En países de Europa del Este y Escandinavia para 1988, entre el 11 y el $17 \%$ de los gerentes y administradores eran mujeres, en tanto que, en Australia, para 1990 el porcentaje ascendía al 23.9\%. Para el caso de Estados Unidos, donde la legislación ha puesto énfasis en romper las barreras de segregación, las tasas de participación se han incrementado de forma importante. Así entre 1979 y 1988 la proporción de mujeres en puestos gerenciales pasó del 30.5 al 38\% (Davidson y Cooper, 1992: 9-10).

Estos análisis reportan además que el acceso a puesto gerenciales en los niveles bajos de las organizaciones no parece ser un problema para la mujer. En cambio, lo que sí ha representado dificultades es acceder a los niveles altos, dentro de la jerarquía corporativa, aún en países como Estados Unidos. Los datos que se tienen para 1990 reportan que en Australia, Estados Unidos y el Reino Unido, el porcentaje de mujeres ejecutivas en puestos de alta dirección oscilaba entre el 1 y el 2\%. Esto significa que aun en estos países las mujeres debían enfrentar lo que se ha llamado "el techo de cristal", cuando intentan acceder a puestos de poder. Este techo de cristal es un obstáculo invisible y no aprehensible, pero que es percibido por las 


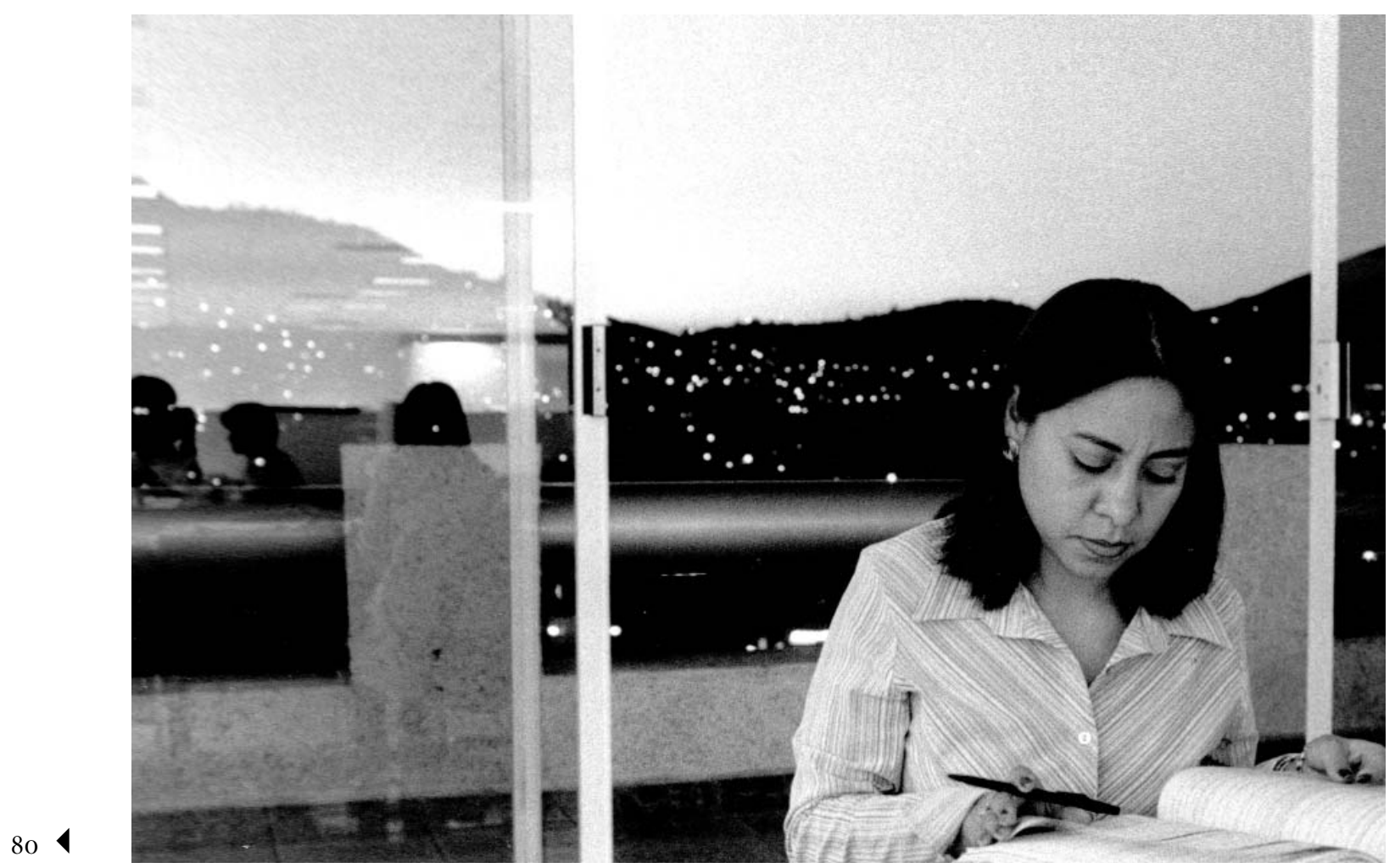

De la serie: Alto, mujeres trabajando, 2003 / Roxana Acevedo

mujeres como una barrera que les impide acceder a los altos niveles de la jerarquía corporativa, aunque en términos de eficiencia profesional sean iguales que los hombres (Davidson y Cooper, 1992: 11-15).

La veta abierta por Mills ${ }^{2}$ en torno a las características de la elite de poder fue retomada por autores como

\footnotetext{
${ }^{2}$ La preocupación por analizar los grupos gerenciales o managers así como a los ejecutivos en puestos de alta dirección fue promovido por Wright Mills en los años cincuenta tanto en su texto White Collar como en The Power Elite. En esa época Mills se interesó especialmente en comprender y analizar el papel que tenían dos grupos que cobraban cada vez mayor importancia en Estados Unidos: los trabajadores de cuello blanco o managers, provenientes principalmente de la clase media y; los accionistas, directivos generales de grandes empresas, los militares y los políticos o la "élite de poder". Para el caso de las mujeres en puestos ejecutivos, en 1962, Felice Schwartz Catalyst fundó una agencia no lucrativa especializada en asuntos que tuvieran que ver con la participación de la mujer en el mercado de trabajo. Con el correr de los años, Catalyst, como se llamó a la institución que se formó con este esfuerzo, desarrollo un objetivo de carácter dual;
}

Zweigenhaft y Domhoff (1998), preocupados por analizar el impacto que han tenido los grupos minoritarios, entre ellos las mujeres, y la composición que mostró esta elite, para el caso de EU a fines de los noventa. En dicho estudio se encontró que lentamente las mujeres habían ingresado a este grupo aunque a fines de los noventa su número era poco significativo comparado con sus homónimos varones.

Para el caso de América Latina estudios pioneros sobre mujeres ejecutivas como los de Arango, Viveros y

por una parte auxiliar a las mujeres que se interesaban en desarrollar sus propios negocios y, por otra, procurar que las mujeres profesionistas maximizaran sus logros y desarrollaran su potencial. La reunión sistemática sobre los logros de las mujeres y las posiciones que iban adquiriendo dentro de la estructura corporativa, política y militar permitió tener una amplia base de datos que, en la década de los noventa se consideró de suma importancia para analizar los cambios que las mujeres norteamericanas habían tenido en ese sector del mercado de trabajo (Zweigenhaft y Domhoff, 1998: 43-44). 
Bernal (1995), realizados en Argentina, Colombia, Chile y Venezuela, reportan que la participación de la mujer en la actividad económica, sobre todo aquellas pertenecientes a estratos medios de la sociedad, se ha ampliado y diversificado de manera importante en las últimas décadas. Para las autoras esto es, en gran medida, el resultado de las crisis económicas en que se han visto envueltas las familias. Pero también es consecuencia de un cambio en las aspiraciones de las propias mujeres, en comportamientos y percepciones distintas respecto a la fecundidad, el trabajo y la familia (Arango, Viveros y Bernal, 1995), lo que coincide con estudios como los de Davidson y Cooper (1992) para países industrializados.

No obstante, el ascenso de las mujeres a cargos directivos en empresas privadas, e incluso del sector público es un fenómeno más o menos reciente en América Latina. La incursión cada vez más evidente de la mujer en puestos directivos en las grandes empresas es, sin duda, el resultado de un proceso lento y conflictivo de modernización de la sociedad. A este incremento porcentual, aunque lento, de la mujer en actividades ejecutivas ha contribuido, sin duda alguna, la expansión de la educación superior y como consecuencia de esto la apertura e incursión de la mujer en actividades profesionales tradicionalmente reservadas a los hombres (Arango y Viveros, 1995).

En México Pérez-Lizaur (2000) llevó a cabo uno de los trabajos pioneros sobre este tema. En este estudio, de corte antropológico, la autora tuvo como propósito elucidar las razones por las cuáles las mujeres ejecutivas de alto nivel permanecían o abandonaban su trabajo. Uno de los hallazgos importantes al analizar las decisiones laborales fue el develar la complejidad que prevalece en el mundo corporativo en donde la tensión entre familia y trabajo se da, en gran medida, por la rigidez y falta de flexibilidad en los horarios a que se ven sometidas como mujeres ejecutivas. Como contraparte de esta situación, se hace énfasis en las estrategias seguidas por las mujeres para permanecer o no en el mundo corporativo en donde la familia extensa parece jugar un papel fundamental. Las situaciones descritas por Pérez-Lizaur para México coinciden con los hallazgos reportados por Arango, Viveros y Bernal para el caso de países del cono sur respecto a la tensión entre el desempeño de una actividad de tipo ejecutivo y el desempeño de su rol familiar como madre.

Como se observa algunos de los análisis sobre el tema que nos ocupa ponen el acento en un incremento en la incursión femenina en este tipo de puestos, misma que, por otra parte, es desigual si se atiende a los distintos niveles de la jerarquía corporativa como ha sido señalado por Davidson y Cooper (1992). Otros en cambio atienden a las razones, estrategias y dificultades que enfrentan las mujeres al combinar el desempeño de una actividad de tipo profesional con horarios poco flexibles y el desempeño de sus responsabilidades familiares. En los estudios plasmados queda claro que el fenómeno que ahora parece extenderse es, en gran medida, producto del proceso de modernización que se vive en los distintos países. Además, en el mundo contemporáneo los procesos de globalización están acompañados del crecimiento de empresas con un verdadero carácter multinacional que tienden a estandarizar a sus cuerpos directivos y gerenciales. Cabría entonces la posibilidad de analizar la consolidación y difusión mundial de estos grupos atendiendo a las propuestas apuntadas por Sassen (1991, 2000), desde la teoría de la globalización. Es decir, como una nueva y compleja dualidad de la organización económica que al mismo tiempo que está dispersa espacialmente, está integrada globalmente y que como corolario ha ocasionado un nuevo tipo de estructura organizacional.

\section{LA DEFINICIÓN DE MUJERES EJECUTIVAS}

Centrarme en las mujeres en puestos ejecutivos, como objeto de estudio, implica necesariamente diferenciarlas de aquellas que se desempeñan como profesionales libres y las dedicadas a actividades de tipo empresarial. Las profesionales libres son mujeres que llevan a cabo, de manera independiente, el ejercicio de un profesión para la que se obtuvieron credenciales específicas. En tanto que las empresarias son actores sociales preocupados por la creación de unidades económicas, por su desarrollo y consolidación acorde con las necesidades de la actividad productiva que realizan y del nicho comercial donde se insertan. En cambio las ejecutivas son, en estricto sentido, 
trabajadoras asalariadas con una elevada escolaridad, cuyas consideraciones de ejercicio son de orden profesional y de competencia y no están estrictamente delimitadas por ellas, sino por la demanda de los propietarios y accionistas de las empresas donde prestan sus servicios profesionales. Esto significa que las decisiones últimas sobre la administración y el desarrollo de la empresa, son ejecutadas por ellas, en razón de las decisiones que toman el consejo de administración y los accionistas (Serna, 1999). Esta definición fue elaborada en un estudio previo que buscaba definir las diferencias entre tres grupos específicos: profesionales libres, empresarias y ejecutivas. En el presente estudio hago uso de aquella definición con el propósito de establecer si tiene relación directa con los actores que se analizan o si es necesario modificarla una vez discutidos los estudios de caso.

Sin embargo, es necesario además tener en cuenta que si atendemos a las propuestas planteadas por Mills sobre los directivos, parte de la elite de poder y los managers o grupos gerenciales, parecería que se trata de dos grupos diferentes que comparten algunas similitudes. Lo que pa- recen compartir es que, en ambos casos, nos referimos a un grupo organizado y graduado jerárquicamente en términos de autoridad para llevar a cabo tareas, planear y ejecutar su propio trabajo y libremente planear y organizar el trabajo de los demás.

En el caso de los directivos o ejecutivos, como lo indica Mills ${ }^{3}$ (1957), son aquellos grupos que "gobiernan el mundo de esas empresas", esto es, quienes toman las decisiones sobre el qué, cómo, cuándo y dónde llevar a cabo una acción específica, la cúspide de la estructura jerárquica corporativa. En términos prácticos esto correspondería a quienes forman parte del recuento anual de Fortune donde se inscriben los Chief Executive Officer (CEO's) o Directores Generales, esto es, los cuadros directivos de las grandes empresas más importantes en el ámbito mundial e incluso en el ámbito nacional de un país, que, para el caso de México serían aquellos que encabezan los

\footnotetext{
${ }^{3}$ De acuerdo con Mills la elite de poder está compuesta por los accionistas o propietarios de las 100 empresas más importantes, los altos directivos (directores general o CEO's) de empresas multinacionales, los militares y políticos de alto nivel.
}

cuadros directivos que reporta Expansión. En tanto que el grupo de managers o gerentes son aquellas personas que, dentro de la estructura jerárquica corporativa, se encuentran en un nivel inferior a los grupos directivos, pero que tienen autoridad y poder para ejercerlo sobre sus subordinados.

Sin embargo, las dificultades sobre considerar a ambos como grupos independientes estriba en que todos se desempeñan en el mundo corporativo que, por otra parte, es considerado como una escalera de ascenso (upper ladder). En esta escalera, algunos de los peldaños dentro de la estructura corporativa agrupan a los niveles gerenciales con diferentes grados de responsabilidad, poder y autoridad y escalones arriba se encontrarían los grupos directivos, también graduados por jerarquía, hasta llegar a la cúspide. Lo que implica que, si bien, parecen grupos diferentes la posibilidad de que una persona en el nivel gerencial transite y llegue exitosamente a ser un director general, parte de la elite de poder, existe. Dejo por ahora planteada la discusión. Considero que es necesario un análisis de las trayectorias de los sujetos y las características de las estructuras corporativas actuales como un medio posible para plantear propuestas claras sobre este tema.

\section{EL ACERCAMIENTO METODOLÓGICO Y LA RECOLECCIÓN DE INFORMACIÓN}

El presente análisis parte de supuesto planteado por Denzin (1970) de que las acciones humanas deben estudiarse y comprenderse desde la perspectiva de los sujetos involucrados en las acciones. Para ello en este estudio hago uso de la herramienta analítica denominada "trayectoria de vida" como un instrumento que nos permite analizar las formas en que los sujetos individuales se constituyen y son constituidos a lo largo de un proceso socio-histórico. Para esta perspectiva la noción central es transición y en ella lo que se hace es observar los cambios cualitativos que tienen lugar en algunos aspectos de la vida diaria del sujeto (Elder, 1989). Por tanto en este enfoque el énfasis está puesto en el contexto en el que se realizan las acciones individuales. Cuando se analizan las trayectorias de vida lo que se hace empíricamente es examinar 
las transiciones que sufren los individuos de distintas categorías sociales o de una categoría social en una cohorte dada. Lo que se hace entonces es analizar la forma en la que los sucesos constituyen cambios en la vida de los sujetos sobre los que se trabaja, de qué manera los acontecimientos sociales afectan la vida del sujeto y cómo sus propias acciones afectan eventos sociales.

Para el presente análisis empleé dos tipos de información. La primera consistió en la recolección y sistematización de datos a partir de fuentes censales, encuestas y otras bases de datos. La segunda, de carácter cualitativo provino de una serie de entrevistas a mujeres que se desempeñaban como ejecutivas en algún puesto de dirección y/o gerencial en empresas nacionales y de carácter multinacional asentadas en la ciudad de México. Por tanto no se trata de una muestra representativa con validez estadística, sino de un conjunto de estudios de caso.

Las entrevistas se realizaron como parte de una temporada de campo que se extendió de enero a octubre del 2001 y en ellas se obtuvo información de carácter general, sociodemográfico así como de la trayectoria familiar, educativa y laboral de las entrevistadas. Planteé en el inicio un total de 30 entrevistas a profundidad, sin embargo, recibí una gran cantidad de cancelaciones a las citas previstas que finalmente no fueron llevadas a cabo. La razón expresada por las mujeres a entrevistar fue, en la mayoría de los casos, lo complicado de sus agendas, lo que condujo a obtener un total de 13 entrevistas con una duración de 45 minutos y en tres casos de una hora. En ninguno de los casos fue posible obtener una respuesta positiva para una segunda entrevista. Esto implicó por tanto que algunas inconsistencias que surgieron al vaciar la información no pudieron ser discutidas de nueva cuenta con la entrevistada.

En todos los casos, antes de concertar una cita, expliqué detalladamente los propósitos de la investigación y que tipo de información requería para llevarla a cabo. También fue necesario dejar claro que la información sería empleada para ejemplificar lo que sucedía en torno al mundo ejecutivo femenino y que se garantizaba una total confidencialidad acerca de su identidad real. Como investigadora me parece importante anotar esto así como explicar las posibles razones por las cuáles no logré

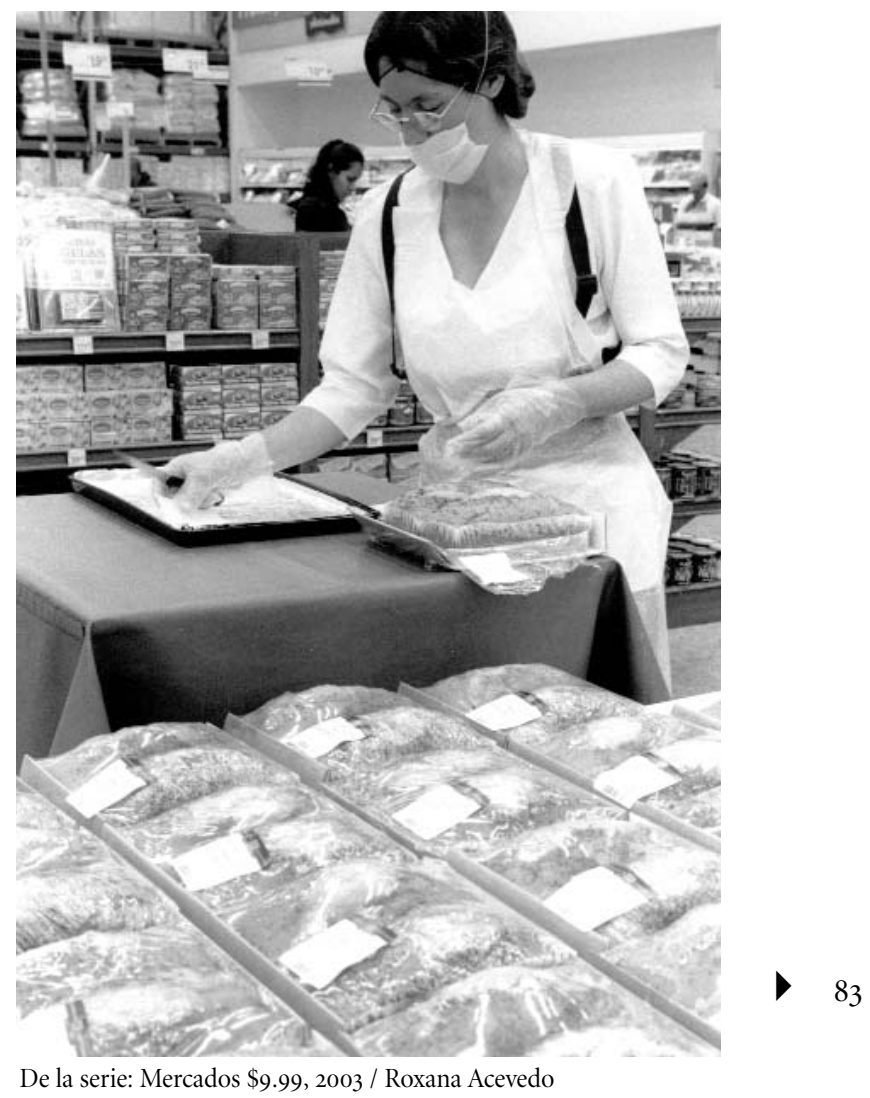

llevar a cabo las entrevistas como se habían programado. Desde mi perspectiva esto se debió a dos razones concretas: a las características del grupo del que me ocupo, que pertenecen a los sectores medios altos y altos con una elevada escolaridad para quienes resultó difícil hablar de sí mismas, de sus acciones, sus preocupaciones y su grupo familiar. En muchos de los casos, a lo largo de la conversación, tenía la impresión de que ellas consideraban que estaba invadiendo espacios de la vida privada. Muy probablemente por esta misma razón hubo quienes no aceptaron concretar una entrevista. La segunda es que, en el mundo donde trabajan las ejecutivas, el tiempo tiene un alto costo monetario, lo que implica que no hay tiempos muertos, ni mucho espacio para conversaciones de tipo informal. Las actividades que realizan están programadas con meses de antelación y, cuando se acepta destinar tiempo, el otro debe ajustarse cuidadosamente 
al horario previsto y no excederse. Asociado al mundo donde se desempeñan para algunas era difícil discutir asuntos de su desempeño profesional ya que su actividad exige de altos niveles de confidencialidad. Como investigadora acepté por tanto que había puntos sobre los que no era posible obtener información.

Es importante anotar que antes de realizar la investigación había establecido contacto con un grupo de mujeres ejecutivas que se reunían periódicamente quienes lograron consolidarse como una asociación en donde, en sus reuniones periódicas, se intercambiaban experiencias y se discutía sobre diversos tópicos de interés para su desempeño profesional. Esto me permitió observar, interactuar con el grupo, así como lograr entrevistas informales, lo cual resultó un apoyo invaluable para la comprensión de lo que significa el desempeño de su actividad profesional, los diferentes problemas que enfrentan, la manera en que los resuelven, así como llenar algunas lagunas de información. Es claro que gracias al apoyo que estas mujeres ejecutivas me brindaron me fue posible establecer los primeros contactos; sin ellas esta investigación no hubiera podido concretarse. Una vez establecidos algunos enlaces las propias entrevistadas me proporcionaron números telefónicos de otras colegas y con ello se abrió la posibilidad de ampliar el espectro más allá del núcleo original.

\section{CAMBIOS EN LA POBLACIÓN EN POSICIONES DE DIRECTIVOS Y FUNCIONARIOS}

De acuerdo con el censo las personas que laboran en puestos de tipo ejecutivo en empresas nacionales o de carácter multinacional se agrupan dentro de la categoría "funcionarios, directivos y gerentes del sector público, social y privado". ${ }^{4}$ Sin embargo, sólo es posible analizar

${ }^{4}$ En el censo de 1990 se definen como trabajadores que realizan actividades directivas, administrativas, normativas y de coordinación en dependencias y organismos gubernamentales en el ámbito nacional, estatal o municipal en instituciones, comercios e industrias públicas y privadas.

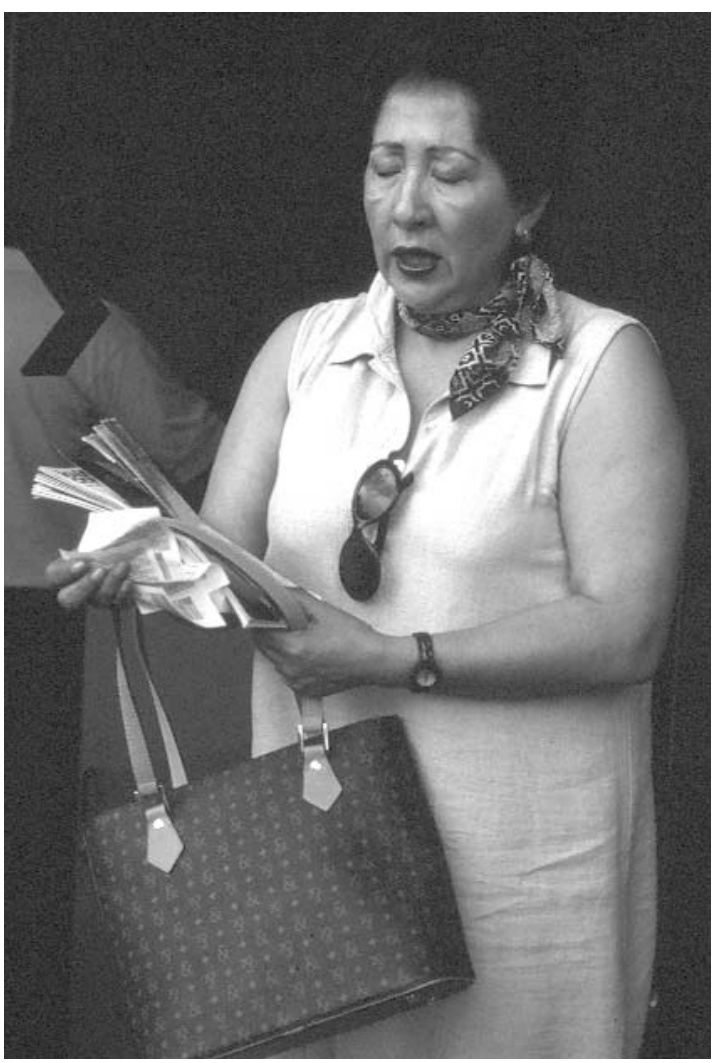

De la serie: Alto, mujeres trabajando, 2003 / Roxana Acevedo

los cambios que este grupo ha tenido entre 1990 y 2000 ya que la información que arrojó el censo de 1970 no es comparable con los posteriores. ${ }^{5}$ Para 1990 en México, del total de la población económicamente activa (PEA) solamente el $2.43 \%$ se desempeñaban como funciona$\operatorname{rios}^{6} \mathrm{y}$ directivos. De este total, el $80.6 \%$ eran hombres y

\footnotetext{
${ }^{5}$ El censo de 1970 solamente registró una categoría "funcionarios y directivos del sector público y privado" y en ella se incluía, además de este grupo, al de supervisores y jefes de departamento. A partir del censo de 1990 se separó a los funcionarios y directivos y se añadió una nueva categoría: "inspectores y supervisores industriales". Para el 2000 a estas categorías se les incorporó la de "jefes y supervisores administrativos".

${ }^{6}$ Es importante tener en consideración que bajo esta categoría se incluyen tres grupos, los funcionarios del sector público, los directivos de la iniciativa privada y los del sector social y que, además, no es posible establecer qué proporción corresponde a unos y otros. Para tratar de definir el número de ejecutivos/as en puestos de dirección en la iniciativa privada es necesario emplear otro tipo de bases de datos.
} 
CUADRO 1

Porcentaje de la población económicamente activa como funcionarios y directivos en México y el Distrito Federal en 1990 y 2000

\begin{tabular}{lcccc}
\hline & & & & 2000 \\
\hline & México & Distrito Federal & México & Distrito Federal \\
\hline Total & 2.43 & 4.64 & 2.23 & 4.38 \\
\hline Hombres & 2.57 & 5.61 & 2.40 & 5.16 \\
\hline Mujeres & 2.0 & 2.79 & 1.87 & 3.14 \\
\hline
\end{tabular}

Fuente: INEGI, XI y XII Censo General de Población y Vivienda y del Distrito Federal

el 19.4\% eran mujeres. Es decir que el porcentaje que representaron las mujeres se encontraba muy por debajo del registrado en países como Estados Unidos, el Reino Unido y Europa Occidental para ese periodo. Por otra parte, el $42 \%$ del total de la PEA como funcionarios y directivos se concentraba en los servicios; ${ }^{7}$ la industria manufacturera, por su parte, concentraba el $21.8 \%$ y el comercio contribuía con el 20 por ciento.

En el 2000 se registró una ligera disminución de la PEA en este tipo de actividades y representó el $2.23 \%$ del total. De este conjunto, el $73.5 \%$ eran hombres y el $26.5 \%$ eran mujeres. Esto significa que a pesar de que hubo un decremento en la PEA como funcionarios y directivos, ${ }^{8}$ tal vez como consecuencia de las crisis económicas en que se vio envuelto el país, la población femenina dedicada a estas actividades registró un incremento importante con relación a la década anterior (véase cuadro 1).

Como había sucedido para 1990, en el 2000 la PEA total de funcionarios y directivos continuó concentrada en los servicios e incluso sufrió un ligero incremento y representó el 43.6\%, en tanto que el comercio concentró el $20.5 \%$ y la industria manufacturera el $16.5 \%$, lo que implicó un decremento importante de ésta última (XI y XII Censo General de Población y Vivienda).

En el caso del Distrito Federal, que es el que nos ocupa, la proporción porcentual que ha mantenido este grupo

\footnotetext{
${ }^{7}$ Para 1990 en el porcentaje de los servicios se excluye los de administración pública y defensa y en el 2000 a las actividades de gobierno. En ningún caso se incluyeron los no especificados.

${ }^{8}$ La PEA en general y por sexo sufrió una disminución. De hecho, la PEA femenina como funcionarias y directivas pasó de $2 \%$ al $1.87 \%$ entre 1990 y 2000.
}

ha sido mayor a la registrada en el contexto nacional. Para 1990 del total de la PEA, el $4.6 \%$ eran funcionarios y directivos, y de ésta, el 69.3\% eran hombres y el 20.7\% mujeres. De este total el 40.2\% se concentró en los servicios en tanto que la industria manufacturera concentró el 24.4\%, mayor al reportado para México y el comercio un $18.35 \%$, ligeramente menor al contexto nacional. Por lo que hace a la PEA femenina como funcionarias y directivas los servicios concentraron el $56.4 \%$, esto es muy por encima del porcentaje registrado para el total de ésta. El comercio contribuyó con el $16.4 \%$ en tanto que la industria manufacturera con un $15.9 \%$, esta última muy por debajo de la reportada para el total de esa PEA (véase cuadro 2).

En el 2000 se registró un ligero decremento y los funcionarios y directivos representaron el $4.4 \%$ del total de la PEA, en donde el $72.2 \%$ eran hombres y el $27.8 \%$ mujeres (véase cuadro 1), lo que significa que el porcentaje de participación femenina se incrementó de manera importante, como sucedió para el contexto nacional. Pero aún más ya que, aún cuando el total de la PEA como funcionarios y directivos sufrió un ligero decremento, en el caso de la PEA femenina en este tipo de ocupación ésta registró un ligero incremento y paso del 2.8 al 3.14\% entre una y otra década (véase cuadro 1). Es decir que, para el caso del Distrito Federal, en la última década las mujeres como funcionarias y directivas registraron un avance importante en términos de participación en el competido mundo masculino de los directivos.

En cuanto al sector de actividad en los servicios se registró un importante incremento con relación a 1990 pues estos concentraron el $49 \%$ del total de esta PEA. Por 
CUADRO 2

Porcentaje de la población económicamente activa como funcionarios y directivos por sector de actividad y sexo en el Distrito Federal en 1990 y 2000

\begin{tabular}{|c|c|c|c|c|c|c|}
\hline \multirow[t]{2}{*}{1990} & \multicolumn{2}{|c|}{2000} & \multirow[b]{2}{*}{ Mujeres } & \multirow[b]{2}{*}{ Total } & \multirow[b]{2}{*}{ Hombres } & \multirow[b]{2}{*}{ Mujeres } \\
\hline & Total & Hombres & & & & \\
\hline Agricultura y ganadería & 0.35 & 0.40 & 0.18 & 0.17 & 0.19 & 0.11 \\
\hline Minería & 0.72 & 0.84 & 0.23 & 0.14 & 0.18 & 0.06 \\
\hline Electricidad y agua & 0.39 & 0.46 & 0.12 & 0.45 & 0.55 & 0.17 \\
\hline Construcción & 4.66 & 5.49 & 1.49 & 3.67 & 4.49 & 1.52 \\
\hline Industria manufacturera & 24.40 & 26.62 & 15.85 & 14.95 & 16.52 & 10.59 \\
\hline Comercio & 18.35 & 18.86 & 16.41 & 19.87 & 20.35 & 18.63 \\
\hline Transportes y comunicaciones & 4.16 & 4.05 & 4.54 & & & \\
\hline Transportes y almacenamiento & & & & 2.74 & 2.93 & 2.23 \\
\hline Información en medios masivos & & & & 4.57 & 4.69 & 4.25 \\
\hline Servicios financieros y seguros & 10.93 & 10.72 & 11.71 & 8.35 & 8.36 & 8.32 \\
\hline Servicios inmobiliarios y alquiler & & & & 2.23 & 2.05 & 2.69 \\
\hline Servicios de apoyo a negocios & & & & 4.67 & 4.33 & 5.54 \\
\hline Servicios profesionales y técnicos & 7.51 & 7.46 & 7.72 & 7.79 & 7.99 & 7.29 \\
\hline Servicios comunitarios y sociales & 10.16 & 6.49 & 24.24 & & & \\
\hline Servicios educativos & & & & 6.63 & 4.0 & 13.46 \\
\hline Servicios de salud y asistencia social & & & & 2.28 & 1.7 & 3.8 \\
\hline Servicios personales y de mantenimiento & 4.27 & 4.40 & 3.77 & & & \\
\hline Servicios de esparcimiento & & & & 1.29 & 1.17 & 1.59 \\
\hline Servicios de restaurante y hotelería & 3.71 & 3.53 & 4.39 & 4.93 & 4.87 & 5.11 \\
\hline Otros servicios excepto gobierno & & & & 3.66 & 3.85 & 3.18 \\
\hline Administración pública y defensa & 5.12 & 5.26 & 4.57 & & & \\
\hline Actividades del gobierno & & & & 7.96 & 8.07 & 7.69 \\
\hline No especificado & 5.28 & 5.41 & 4.77 & 3.65 & 3.61 & 3.76 \\
\hline
\end{tabular}

Fuente: INEGI, XI y XII Censo General de Población y Vivienda del Distrito Federal

su parte en el comercio el porcentaje fue del $19.87 \%$, con un ligero incremento, en tanto que en la industria manufacturera se registró una participación mucho menor con el 15\%. Con relación a la situación de la PEA femenina como funcionarias y directivas tenemos que, durante el 2000, la concentración de ésta en los servicios sufrió incluso un ligero incremento y representó el 57.5\%, seguido del comercio con un $18.6 \%$, en tanto que en la industria manufacturera el porcentaje se redujo de manera importante y representó sólo el 10.6\% (véase cuadro 2).

Para completar el cuadro de cambios en el grupo de funcionarios y directivos es necesario incorporar una variable más, la que atiende al nivel de instrucción en estos grupos. De acuerdo con la Encuesta Nacional de
Empleo (ENE), para $1996^{9}$ el $21.5 \%$ del total de la población económicamente activa ocupada (PEAO) contaba con un nivel de instrucción medio superior y superior y éste se incrementó hasta llegar al 24.5\% en el 2000. Al concentrarnos en la PEAO como funcionarios o directivos se observa que, para 1996, el 73\% de ellos contaba con un nivel de instrucción medio superior y superior. Por lo que hace al Distrito Federal encontramos que para 1996 el $40.6 \%$ del total de la PEAO tenía ese nivel de escolaridad y que para el 2000 representó el $41.5 \%$, es decir, casi el doble de lo reportado para el conjunto de las zonas

\footnotetext{
${ }^{9}$ En el conjunto de las zonas metropolitanas.
} 


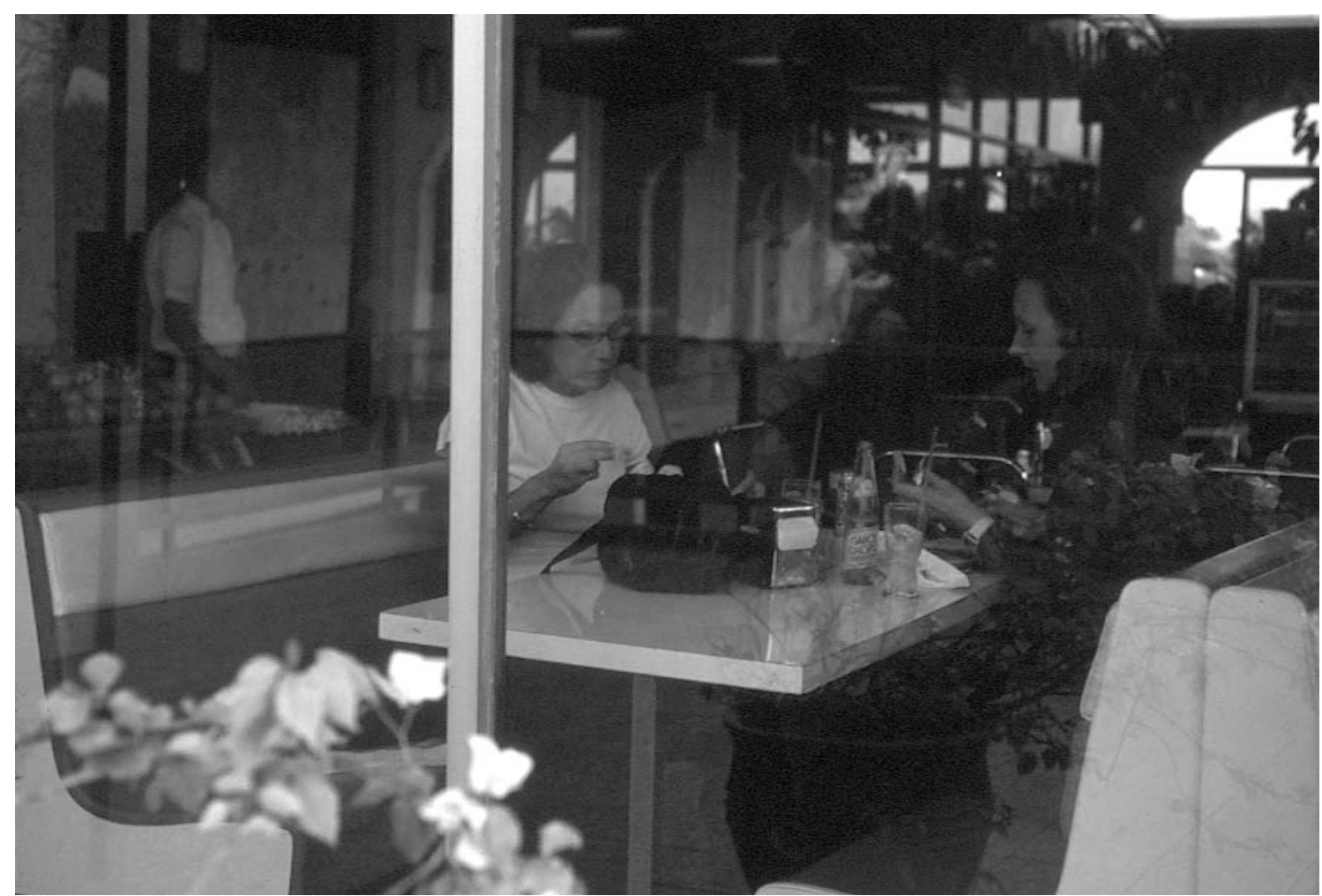

De la serie: Alto, mujeres trabajando, 2003 / Roxana Acevedo

metropolitanas. En el caso de la PEAO como funcionarios y directivos el $80.3 \%$ del total se concentraba en este nivel de instrucción, en 1996, incrementándose hasta el $91.4 \%$ en el 2000. Este porcentaje tan alto de personas con este nivel de escolaridad así como su incremento constante dejan ver que los requisitos para incorporarse a este tipo de actividad exigen contar, al menos, con un título profesional. En el caso de la PEAO femenina como funcionarias y directivas se registró también un incremento significativo en este nivel de escolaridad, pues pasaron del 65.7\% en 1996 al 79.2\% en el 2000.

Tenemos entonces que en el Distrito Federal, prácticamente, el 50\% del total de los funcionarios y directivos, donde la mayoría de ellos cuentan con una escolaridad media superior y superior, se localizan en los servicios. Pero los cambios que han tenido lugar en este grupo son aún más evidentes si analizamos con detalle el cuadro 2. En este es posible observar que el tipo de servicios que concentra la mayor participación de esa PEA, en la última década, son aquellos denominados servicios al productor, desplazando de manera importante a la industria manufacturera y manteniendo en auge al comercio. Esto es un indicador de que la Ciudad de México se está convirtiendo en un lugar cuya actividad principal parece ser la producción de servicios especializados a las grandes empresas y representaciones de corporaciones asentadas en ella. La reestructuración del empleo en este sentido y las nuevas funciones que anuncia marcan ya, al parecer, la entrada de esta zona en una nueva fase económica.

Como una muestra más de estos cambios y de las características tan particulares que tiene la Ciudad de México con relación a otras grandes ciudades en México podemos añadir que para 1998 el 50\% de las empresas más importantes de México —en términos de ventasestaban asentadas en esta zona (Parnreiter, 2000:198) y 


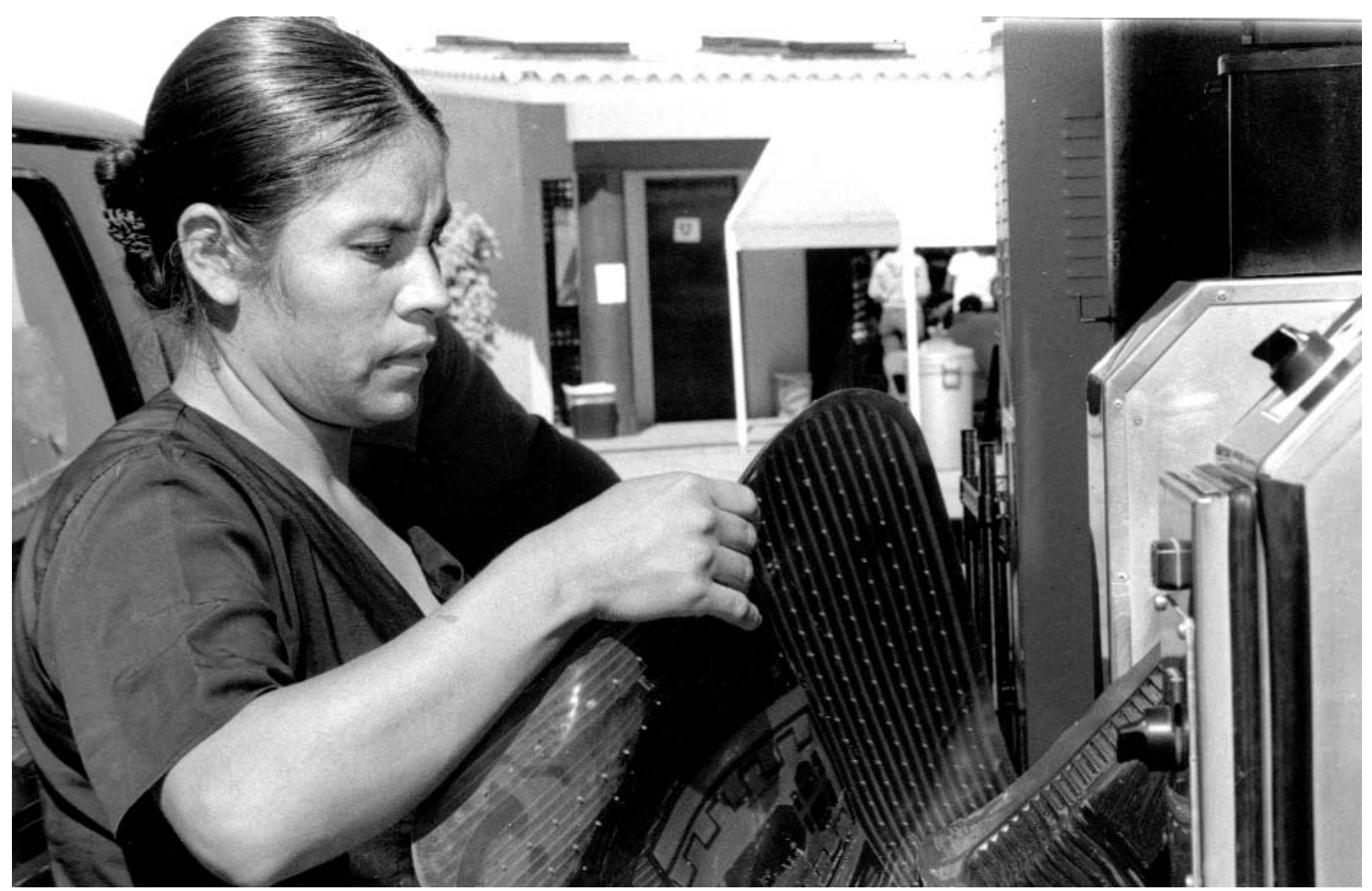

De la serie: Alto, mujeres trabajando, 2003 / Roxana Acevedo

para el año 2000, de acuerdo con los datos de Expansión este porcentaje se incrementó hasta el 59\%.10 Esto implica que la proporción más importante de directivos y gerentes se localiza también en la Ciudad de México (Expansión. Las 500 empresas, 2000 y 2001).

\section{LA ZONA DE ESTUDIO}

Los distintos estudios que he abordado permitieron configurar un panorama general de las mujeres que se desempeñan como ejecutivas, en tanto que los datos censales

\footnotetext{
${ }^{10}$ Los municipios del Estado de México que se incluyen aquí son: Atizapan, Naucalpan, Tlalnepantla, Cuautitlán, Chalco, Ecatepec, Tultitlán y Tepotzotlán. Parnreiter (2000) estima, a partir de los datos de Expansión, que para 1998 el $42 \%$ de las empresas más importantes de México en términos de ventas estaban asentadas en el Distrito Federal. Basada en la misma fuente mi estimación para el 2000 fue de un 53 por ciento.
}

aportaron información sobre el panorama que guarda este grupo en México y el Distrito Federal. En el presente apartado y los siguientes me interesa plantear los primeros hallazgos provenientes de la información de campo recopilada.

Las grandes empresas nacionales y de carácter multinacional donde laboran las mujeres ejecutivas, a las que este estudio se refiere se ubican, sobre todo, en el oeste y noroeste de la Ciudad de México en las delegaciones Miguel Hidalgo, Álvaro Obregón y Cuajimalpa. Así la zona de Polanco, a lo largo de Paseo de la Reforma, Paseo de las Palmas, Bosques de las Lomas, Paseo de los Laureles y Santa Fe, en su conjunto, se han convertido desde fines de los ochenta y particularmente en los noventa, en lugares donde predominan grandes edificios de cristal, los llamados corporativos, que dan un carácter muy diferente al que prevalece en el resto de la Ciudad de México. En menor medida, algunas zonas del sur, cercanas al Periférico, también muestran cambios pues se han asentado 
estos edificios de cristal, algunos de ellos "inteligentes", que albergan oficinas de grandes empresas tanto mexicanas como multinacionales.

La mayoría de las mujeres ejecutivas, viven muy cerca de la zona donde trabajan. Algo que vale la pena destacar es que un grupo importante no vive en el Distrito Federal, sino en los municipios colindantes con la zona metropolitana como Naucalpan y Huixquilucan, del Estado de México. Viven en fraccionamientos residenciales, condominios o complejos departamentales que se ubican en Lomas de Tecamachalco, La Herradura, El Country Club, Lomas de Vista Hermosa y Bosques de las Palmas, o en lugares más distantes de la zona de trabajo como Ciudad Satélite Poniente. Otras han preferido vivir dentro del Distrito Federal, en delegaciones como Álvaro Obregón, Miguel Hidalgo y Benito Juárez en las Lomas de Chapultepec, Santa Fe, la Condesa o Las Águilas.

En este caso se trata de zonas en donde tradicionalmente se han asentado los estratos medios-altos y altos o bien, de nuevas zonas urbanas residenciales con guardias de seguridad, grandes espacios, áreas verdes, alejadas del ruido donde el flujo vehicular contrasta significativamente con el que normalmente deben enfrentar la mayoría de los habitantes de la Ciudad de México. Esto también implica que los traslados cotidianos son en distancias cortas y generalmente sin tráfico.

\section{CARACTERÍSTICAS GENERALES DE LAS MUJERES EJECUTIVASY SUS FAMILIAS DE ORIGEN}

En este apartado me interesa discutir las características que tienen algunas mujeres que ocupan puestos de tipo ejecutivo en varias empresas en la Ciudad de México, empleando para ello la información recopilada a lo largo del trabajo de campo. Con ello espero mostrar que la forma en que se han insertado al mercado laboral y el tipo de actividad profesional que realizan en las grandes empresas donde trabajan las coloca como un grupo que no habría tenido cabida en este mundo masculino de ejecutivos de la Ciudad de México dos décadas atrás.
La mayoría de las entrevistadas son mujeres jóvenes que nacieron en los sesenta y al inicio de los setenta. Siete de ellas ${ }^{11}$ tienen entre 29 y 33 años, cinco entre 35 y 39 y sólo una 44 años. Se trata por tanto de mujeres jóvenes que se incorporaron al mercado de trabajo durante la década de los ochenta y a lo largo de los noventa. En este caso el grupo analizado corresponde con los datos reportados para mediados de los noventa donde se registra que, entre las funcionarias y directivas, el 80\% se concentraban en los grupos de entre 20 y 49 años de edad (INEGI, Estadísticas de empleo con enfoque de género, 1999). Esto también refuerza los hallazgos de autoras como García de Oliveira (1994), para el caso de México, quien indica que la mujer permanece en la actividad económica independientemente de su estatus marital.

Al urgar sobre los lugares donde habían nacido encontré que el grupo estaba conformado también por extranjeras. Del total de entrevistadas ocho eran mexicanas, al igual que sus padres. Siete de ellas nacieron en la Ciudad de México y una en provincia, aunque en dos casos la familia paterna había llegado a México dos generaciones atrás procedente de algún país europeo. De las otras cinco, dos eran ciudadanas estadounidenses. En el primer caso sus padres son estadounidenses y se establecieron en la Ciudad de México por razones de negocios. Ella nació y creció en México aunque sus estudios profesionales los cursó en una universidad estadounidense. Al concluir regresó a México donde ha permanecido trabajando. En este caso ella no consideró como posibilidad obtener la ciudadanía mexicana. La otra es hija de una mexicana y un caribeño quienes se habían conocido en México, adonde él viajaba con frecuencia por razones de negocios. Al casarse se establecieron en Estados Unidos, donde la entrevistada nació. Años después la familia se trasladó a México en donde ella estudió parte del bachillerato. Antes de alcanzar la mayoría de edad regresó a Estados Unidos donde continuó estudiando y concluyó sus estudios universitarios, optando por la nacionalidad estadounidense al ser mayor de edad. Años después la compañía donde trabajaba la trasladó a su sede en la

\footnotetext{
${ }^{11}$ En todos los casos el presente se refiere al año 2001.
} 
Ciudad de México. La tercera es una mujer originaria de un país de Latinoamérica cuyos padres tenían nacionalidades diferentes por lo que ella conserva tanto la nacionalidad de su madre, como de su padre. Después de haber vivido en diferentes países, a donde se trasladó por razones de trabajo, llegó finalmente a la Ciudad de México y ha permanecido por varios años desempeñando distintos puestos de alta dirección en empresas multinacionales. La cuarta es una mujer hija de una mexicana y un español. Aunque ella nació en un país centroamericano a donde se trasladaron a vivir sus padres, por razones de negocios, cuando llegó a la mayoría de edad optó por la ciudadanía española. Finalmente, el último caso es una mujer de origen nórdico cuyos padres llegaron a vivir a México, antes de que ella naciera. Cursó sus estudios básicos y medio superiores en México pero salió al extranjero a cursar su licenciatura, posteriormente, regresó a trabajar en México. Ella es el único de los casos que mantiene la nacionalidad de su familia de origen y la mexicana.

Llama la atención que aquellas mujeres cuya madre era mexicana hayan optado por una tercera nacionalidad, la del país donde nacieron. $\mathrm{Al}$ ahondar sobre este punto la razón principal que argumentaron fue que esa nacionalidad les ofrecía algunas ventajas, como por ejemplo, una educación en el extranjero, o bien, mayores posibilidades de trabajar en distintos países, decisión en la cual los padres tuvieron un papel relevante. También es claro que, en el caso de las extrajeras nacidas en México, se ha optado por tener la misma nacionalidad que sus padres y sólo de manera excepcional se ha contemplado la posibilidad de mantenerse, además, como mexicana. Es probable pensar que esto tiene que ver con formas de pensar, más o menos generalizadas en los estratos medios altos $\mathrm{y}$ altos que suponen que el tener una nacionalidad específica abre más puertas que otras. En este sentido, parecería que es una desventaja el contar con una sola nacionalidad, concretamente la mexicana, para laborar en grandes empresas de carácter multinacional. De hecho del conjunto de estudios de caso analizados solamente una mexicana, con apellido paterno extranjero, se encuentra en un puesto de dirección importante y, el resto de mexicanas, en cambio, ocupan puestos de menor importancia en relación con las extranjeras. No obstante, no cuento con elementos suficientes para afirmar que existen ventajas claras por el hecho de mantenerse como extranjera, ya que el número de casos es muy reducido. Aunque sin duda éste es un problema sobre el que hay que profundizar para establecer qué cambios ha traído en el mercado laboral la proliferación de corporativos multinacionales que establecen sedes en las grandes ciudades de distintos países. Cabría preguntarse si esto es el signo de los nuevos tiempos y estos cambios están en relación con lo que se ha denominado el proceso de globalización que se vive en el mundo contemporáneo.

La composición de la familia de origen de estas mujeres es también muy particular pues provienen de familias con un número reducido de hijos, en donde, la formación de estos hogares tuvo lugar a fines de los cincuenta y durante los sesenta. En dos casos se trata de familias donde ellas son hijas únicas, una es mexicana y otra extranjera. Ocho más cuentan con entre uno y tres hermanos y se incluye tanto a familias mexicanas como extranjeras. Finalmente en tres casos tienen cuatro hermanos y se trata de familias mexicanas. Son en su mayoría familias pequeñas en donde el número máximo de integrantes es de seis, incluidos los padres.

Con respecto al estatus marital de sus padres en ocho casos continúan casados, aunque en uno se trata de un segundo matrimonio, como consecuencia de una viudez temprana. En tres casos las madres han quedado viudas y así se han mantenido y, en dos más, los padres se divorciaron y no han vuelto a contraer matrimonio.

En relación con la profesión y/o ocupación del padre, nueve de ellas son hijas de hombres que se dedican a la actividad empresarial en diversas áreas como los servicios, las manufacturas y el comercio. Las otras cuatro son hijas de asalariados profesionales que prestan sus servicios tanto en instituciones gubernamentales como en empresas privadas. La mayoría de ellos cursaron estudios de licenciatura y posteriormente abrieron su propio negocio, o bien, se incorporaron como profesionales asalariados. En cambio, en el caso de la madre, sólo algunas cursaron estudios de licenciatura y otras concluyeron la preparatoria. De hecho nueve de ellas se han dedicado fundamentalmente a la coordinación de las 


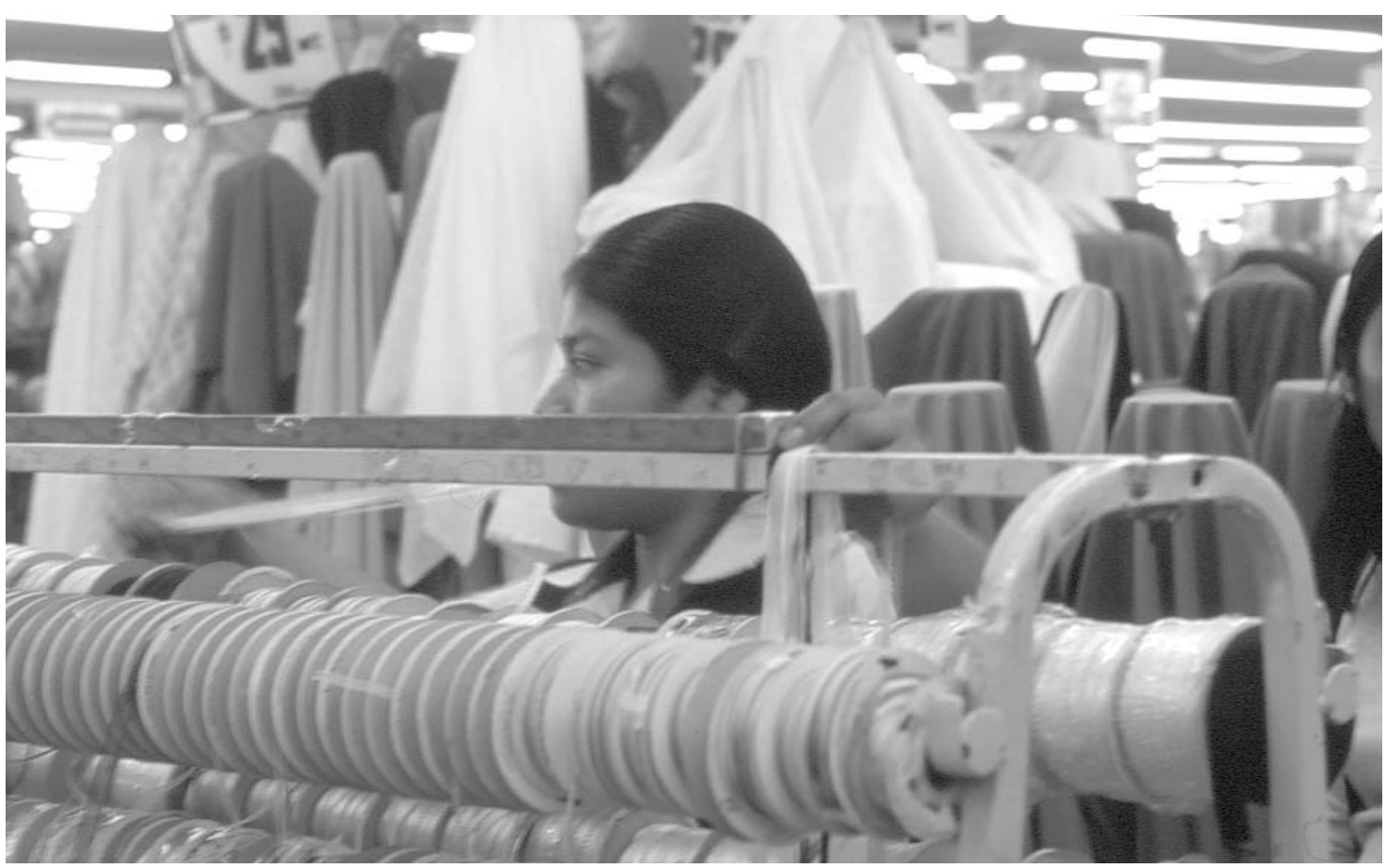

De la serie: Alto, mujeres trabajando, 2003 / Roxana Acevedo

actividades del hogar y al cuidado de los hijos y sólo cuatro se mantienen en la actividad económica. De este conjunto, en tres casos, la madre ha trabajado de manera ininterrumpida desde antes de contraer matrimonio, al mismo tiempo que se responsabilizaba de su hogar e hijos. En el otro caso su incorporación a la actividad económica, vía la formación de su propia empresa, tuvo lugar una vez que los hijos crecieron.

\section{TRAYECTORIAS EDUCATIVAS}

En términos de educación el grupo de entrevistadas comparte al menos tres elementos. En todos los casos su educación hasta la universidad e incluso después de esta fase, se realizó en instituciones privadas; sin excepción todas cuentan con un título de licenciatura y; todas son al menos, bilingües.

En cuanto a su educación básica y hasta la preparatoria una gran parte de ellas estuvieron en colegios privados con educación bilingüe, generalmente en inglés y español, que tenían una amplia tradición de albergar a sectores con cierto poder adquisitivo. Éste sería el caso de colegios e institutos como el Moderno Americano, el Liceo Francés, el Vistahermosa, Vallarta, Regina u Olinca, por mencionar algunos. En el caso de sus estudios universitarios todas estudiaron en universidades de carácter privado como La Salle, Anáhuac e Iberoamericana, otras, en cambio, estudiaron en universidades estadounidenses, al norte de Estados Unidos o bien en Europa.

En relación con el tipo de carreras de donde provienen, dos de ellas son ingenieras, una en cibernética y otra en química. Ocho cursaron carreras como contaduría, informática, relaciones internacionales o industriales, derecho, o bien, economía Finalmente, tres provienen de carreras como publicidad y diseño gráfico y una más estudió arquitectura. Dadas las características del tipo de trabajo que desempeñan y para lograr un ascenso a mejores posiciones dentro de las compañías donde trabajaban algunas de ellas cursaron estudios de posgrado, $\mathrm{o}$ 


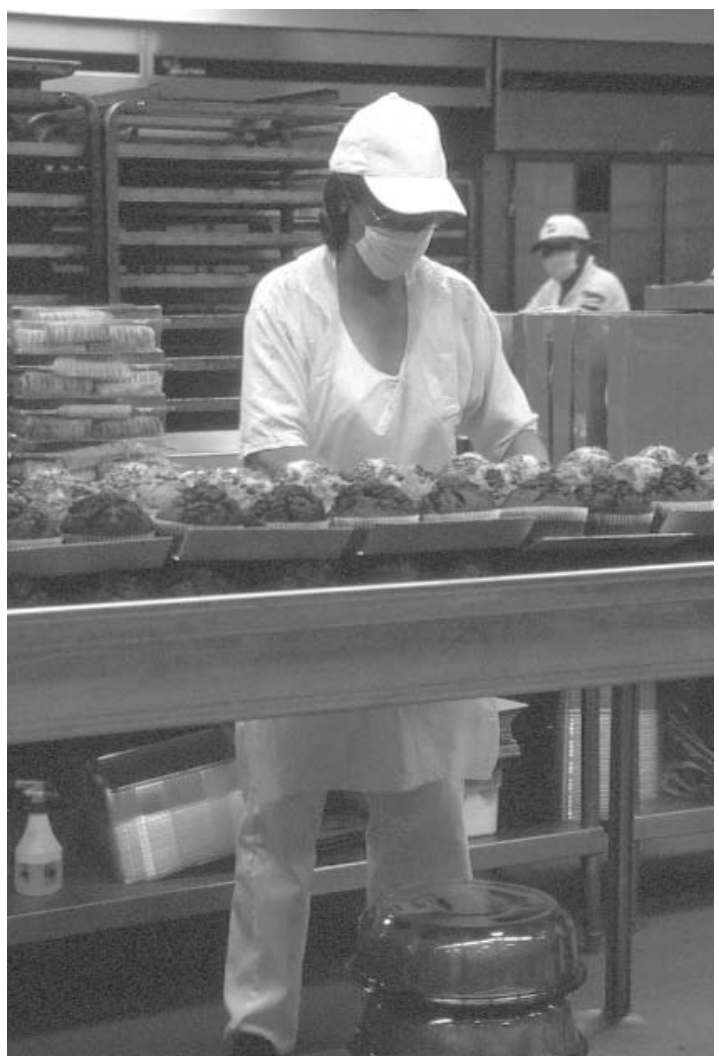

De la serie: Mercados \$9.99, 2003 / Roxana Acevedo

bien, algún diplomado. Del total de entrevistadas, cinco tenían una maestría en asuntos relacionados con administración de empresas, finanzas, bienes raíces o bien derecho corporativo y dos más cursaron un diplomado en bienes raíces y en recursos humanos en instituciones como el IPADE, el ITAM, el ITESM o bien en algunas universidades estadounidenses como Cornell o Yale.

Prácticamente la mitad de ellas hablan dos idiomas, además del materno y los más comunes son el inglés, francés, alemán y español. No hay que olvidar que, en varios casos, la comunicación entre los miembros de la familia no es en español y en otros casos la familia interactúa con gran facilidad en inglés. Se trata por tanto de un grupo fuera de la media nacional, tanto por su elevada escolaridad como por su desempeño lingüístico. Esto se mantiene incluso si atendemos a las cifras que arroja el censo para el grupo de funcionarias y directivas, ya que el total del grupo analizado contaba con educación superior y una parte de ellas, además, con estudios posteriores.

La trayectoria educativa seguida por este conjunto de casos también confirma que se trata de un grupo que proviene de familias de estratos acomodados, hijas de profesionistas, donde hay un interés particular de los padres de ofrecer una educación privada, como lo expresaron ellas mismas. Esto en gran parte se debe a que, desde la perspectiva de los padres y de ellas mismas, este hecho abre la posibilidad de acceder a un tipo de trabajo difícil de lograr si se tiene una educación de carácter público. Aunado a esto, el hecho de formar parte de una red de personas vinculadas a actividades económicas similares gracias a las múltiples relaciones familiares y de negocios, les ha facilitado en gran medida su incorporación a empresas específicas. Esto además de las relaciones adquiridas por ellas mismas en las instituciones donde estudiaron.

\section{SITUACIÓN FAMILIAR ACTUALY DESEMPEÑO LABORAL}

En relación con el estatus marital de este conjunto, nueve de ellas están actualmente casadas y en tres casos se trata de segundas nupcias. Cuatro de ellas son solteras y una se divorció ${ }^{12}$ recientemente. Del grupo de ejecutivas casadas, sólo cinco tienen hijos entre doce y menos de un año de edad. En los otros casos, ellas expresaron haber tomado la decisión de no tener hijos y dedicarse de tiempo completo a su trabajo. Por lo general se trata de parejas dedicadas a actividades similares que viajan constantemente o bien, son profesionales independientes al frente de algún despacho. En el caso de las mujeres que permanecen solteras, expresaron dificultades para mantener una relación por periodos largos. Entre las razones de esto se encuentran los horarios de trabajo y constantes viajes, así como la dificultad para que un hombre

\footnotetext{
${ }^{12}$ Expresado por ellas mismas, una vez divorciada, vuelves automáti-
} camente a una condición de soltería. 
acepte que su salario es elevado, o bien, que continuarán trabajando al mismo ritmo una vez casadas.

En cuanto al momento en que se incorporaron a la actividad económica, ocho de ellas lograron su primer empleo a temprana edad, cuando tenían entre 17 y 20 años y aún estudiaban. Lo hicieron por iniciativa propia ya que estaban interesadas en "empezar a hacer otras cosas" e irse integrando al mundo del trabajo, o bien, contar con dinero propio - aunque sus familias no lo exigían. Iniciaron como recepcionistas o asistentes, aprovechando sus habilidades lingüísticas, en algún despacho o firma de servicios que requería de personas con cierta calificación que trabajaran por horas o, medio tiempo. La estancia promedio en ese tipo de trabajos iniciales varió de entre seis meses a dos años, como máximo. A partir de esta primera experiencia de trabajo el siguiente empleo que reportaron ya estaba relacionado directamente con su carrera profesional. Las otras cinco se iniciaron en la actividad económica más tarde a los 22 ó 23 años de edad, cuando estaban por concluir su carrera. En estos casos fue, a sugerencia de sus profesores, una manera de adquirir experiencia en el mundo práctico. Varias iniciaron como becarias, otras como analistas y casi todas permanecieron en esa misma compañía por algunos años.

Algunas de estas mujeres ejecutivas se incorporaron al mundo del trabajo, en ocasiones, gracias a las redes de su familia de origen, en donde los amigos y conocidos desempeñaron un papel importante para lograr vincularse a alguna compañía que requería el perfil profesional que ellas tenían. Para otras, en cambio, fue decisivo el que sus profesores se preocuparan por colocar a sus egresadas en un empleo aprovechando sus contactos y el conocimiento que tenían de las empresas. Si tomamos esto en consideración, resulta cierto lo que ellas mismas indicaron: que el estudiar en instituciones de carácter privado en México abre un nicho de oportunidades en donde, al parecer, las instituciones públicas no han logrado insertarse.

La información recopilada indica que una vez que tenían un empleo de tiempo completo y formal, dentro de una empresa, había una serie de puestos por los que se debía transitar para ascender dentro de la organización. Estos puestos tienen diferentes nombres, por lo que hay dificultades para determinar con certidumbre el ascenso.
Por otra parte, por regla general, las equivalencias de puestos la llevan a cabo compañías privadas de compensación tomando en cuenta tanto las percepciones salariales como los beneficios que obtendrá y, por ahora, no se ha tenido acceso a este tipo de información. Por tanto, es importante tener en cuenta que, en este caso concreto, el cambio y ascenso de las mujeres ejecutivas corresponde a su propia interpretación.

El puesto de analista, como asistente de planeación estratégica o soporte de ventas, es de los primeros a que se accede; puerta de entrada al mundo ejecutivo es el primero relacionado con su profesión. En la mayoría de los casos analizados la permanencia en este puesto varió de entre seis meses hasta dos años, acorde con su desempeño. Una vez obtenido un ascenso pasaban a ser managers o gerentes, bien de marca, de cuentas mayores, de productos, de diseño o de reclutamiento y selección de personal. Para las entrevistadas el permanecer entre uno o dos años en el cargo fue considerado como "un tiempo razonable", pero el prolongarse por más tiempo marcaba el inicio de búsqueda hacia nuevas opciones, lo que sucedió en algunos de los casos. El ser manager o estar al frente de una gerencia es, al parecer, el primer puesto requerido para ingresar a una "carrera real de ascenso" en las grandes empresas nacionales y multinacionales. De hecho quienes eran gerentes y abandonaban su puesto, al ingresar a otra compañía, volvían a ocupar una gerencia, aunque ahora con mejores percepciones salariales y compensaciones.

La posición de gerente de división o senior manager para una región, de operaciones o de organización es el siguiente escalón al que se aspira y es a quienes reportan directamente las gerencias. En este puesto se tiene a su cargo un mayor número de personal, una cobertura más amplia y contacto directo con la subdirección de división, o bien, en organigramas matriciales incluso con la dirección general de la zona. De nueva cuenta en este puesto se considera que un lapso no mayor de dos años es razonable, pero si hay un buen desempeño en un año se ascenderá. Algunas entrevistadas indicaron que es aceptable pasar a otra gerencia de división ya que se amplía su rango de acción y se obtiene mayor experiencia. Al parecer a partir de este puesto y los posteriores de nivel 


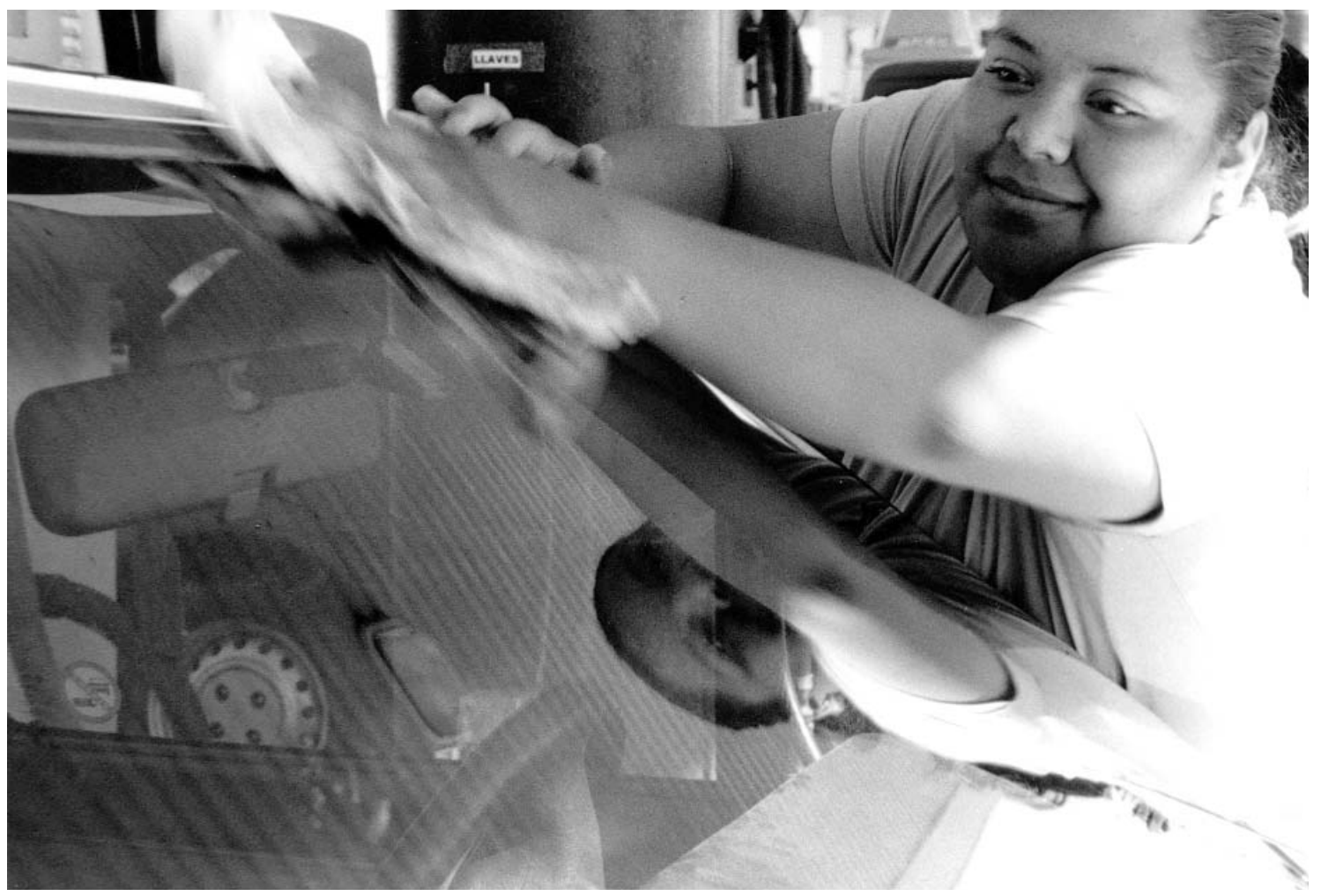

De la serie: Alto, mujeres trabajando, 2003 / Roxana Acevedo

subdirección y dirección, la percepción salarial es un asunto que se negocia y puede ser una razón para dejar una empresa e incorporarse a otra. Aunque también son de suma importancia las compensaciones que se obtienen ya que estas pueden incluir el uso de un automóvil, el pago de un club deportivo, vacaciones, bono anual, pago de guardería o colegios e, incluso, renta de una casa.

El obtener una subdirección o tener una posición de manager corporativo de una división de negocios, de ventas, de riesgos o de comunicación es un logro importante para una mujer que se desempeña en el mundo corporativo. Al igual que en el caso anterior, se puede rotar dentro de las distintas subdirecciones para adquirir experiencia pero lo importante es ascender. En el grupo analizado éste es el último peldaño en donde se localiza una gran parte de las entrevistadas. En orden ascendente le sigue la dirección de división, de ventas y negocios, de producción, de finanzas o de servicios. En este caso, de acuerdo con la estructura de la empresa reportan directamente al director general o Chief Executive Offcer (CEO). En algunos casos la persona en este puesto forma parte del grupo que se reúne a discutir directamente con el director general o CEO de la matriz. En este caso, tres de las entrevistadas, todas con entre diez y 15 años de trabajar como ejecutivas, han logrado llegar a este puesto. Para las entrevistadas en este punto se localiza el denominado "techo de cristal", ya que pretender una dirección general resulta, para una mujer ejecutiva, algo excepcional. Desde luego, el hecho de que solamente el $2 \%$ del total de mujeres ejecutivas en México sean directoras generales apoya esta idea (Expansión, 2001).

Por otra parte, el total de las ejecutivas entrevistadas trabajaban en empresa y corporativos de carácter multinacional en donde la mayoría de ellas ofrecen servicios especializados al mundo empresarial de tipo bancario, 
financiero, de comunicaciones, de asesoría en informática, legales de tipo corporativo, o bien de atención a eventos y hospedaje. Sólo en dos casos se registró una empresa en el sector de la química y otra con múltiples negocios que iban desde la industria manufacturera, pasando por servicios financieros hasta llegar a bienes raíces. ${ }^{13}$

En relación con el tiempo en que se han desempeñado como ejecutivas, en seis casos tenían entre seis y nueve años y siete entre 11 y 17 años de participar en la actividad económica. Es decir que su ingreso al mercado de trabajo tuvo lugar a mediados de los ochenta y durante los noventa. De ahí que se pueda considerar como uno de los primeros grupos que se incorporó a este tipo de empleo en este tipo de empresas. En cuanto al tiempo de estancia en una misma compañía, encontré que hay una gran movilidad, ya que se registraron entre cinco y seis cambios en el tiempo que llevan de trabajar, esto es, al menos dos años en la misma empresa. De hecho, solamente dos permanecieron por casi 12 años en la misma empresa, hasta lograr un puesto de subdirección.

Las razones que expresaron las ejecutivas para cambiar de empleo fueron, en la mayoría de los casos, una mejora en sus condiciones laborales; el no obtener la promoción esperada, que implicaba para ellas "no crecer profesionalmente". Éste es un punto difícil pues para ello se depende del superior, generalmente un hombre, y en estas circunstancias, las posibilidades de formar equipos al parecer disminuyen para las mujeres. En ningún caso las razones estuvieron ligadas a sus largas y extenuantes jornadas de trabajo, a la frecuencia con que se trasladan de un país a otro, al gasto que representa su vestimenta profesional, o bien a tener que comer diariamente en restaurantes por el tipo de horarios poco flexibles que deben cubrir. Para ellas todo esto forma parte del trabajo que una ejecutiva debe hacer, por lo que no resulta extraño el que se trabaje más de diez horas diarias y se empleen, los fines de semana, para trasladarse a reuniones en otros países.

${ }^{13}$ Los nombres de las empresas han sido omitidos a propósito para garantizar la confidencialidad de los informantes.

\section{ALGUNAS CONSIDERACIONES FINALES}

El estudio de las mujeres en puestos ejecutivos presenta retos importantes, donde el punto nodal es: ¿cómo acercarse al estudio de estos grupos que forman parte de los sectores medios altos y altos tan poco analizados en nuestro país? En este texto he intentado recuperar y discutir algunos de los hallazgos que el presente proyecto ha logrado. Presenté para ello un bosquejo general en el que el interés fue dar una imagen si bien, muy general, que tocara los puntos que considero debe incluir un estudio sobre mujeres ejecutivas, para el caso de México.

Se trata de un grupo femenino de actores económicos y sociales que, para inicios del siglo XXI aparece claramente definido, aún cuando la proporción porcentual que guarda con sus homónimos varones sea muy contrastante, al menos por ahora. También es claro que su incursión en el mercado de trabajo es muy reciente, difícilmente excede las dos décadas, en este tipo de puestos gerenciales y directivos. Al igual que es evidente que este ha tenido cabida en la medida en que las mujeres, en este caso de los estratos acomodados, han logrado concluir estudios profesionales y mantenerse en la actividad económica, aún cuando tengan responsabilidades familiares. Para completar el cuadro, en el caso de la Ciudad de México también han contribuido a ello el incremento en los servicios al productor, y que ha resultado un nicho de inserción para estas mujeres, a pesar de la competencia masculina.

No obstante, el camino de ascenso está aún plagado de dificultades. Uno de ellos es el ascenso dentro de la jerarquía corporativa y que indica que en aquellos grupos donde el superior inmediato es un hombre las promociones para las mujeres que conforman el equipo son reducidas. En estas empresas se viven en aparente igualdad, pero en el fondo la práctica cotidiana parece ser la desigualdad. La información indica que una vez que ingresan las futuras ejecutivas a las empresas éstas se incorporan a complejos procesos de entrenamiento procediendo a la rotación de puestos en diversas áreas y departamentos. Sin embargo, en el conjunto de casos descritos esta rotación apenas si tiene lugar, ya que el tiempo que permanecen en la corporación suele ser poco. 


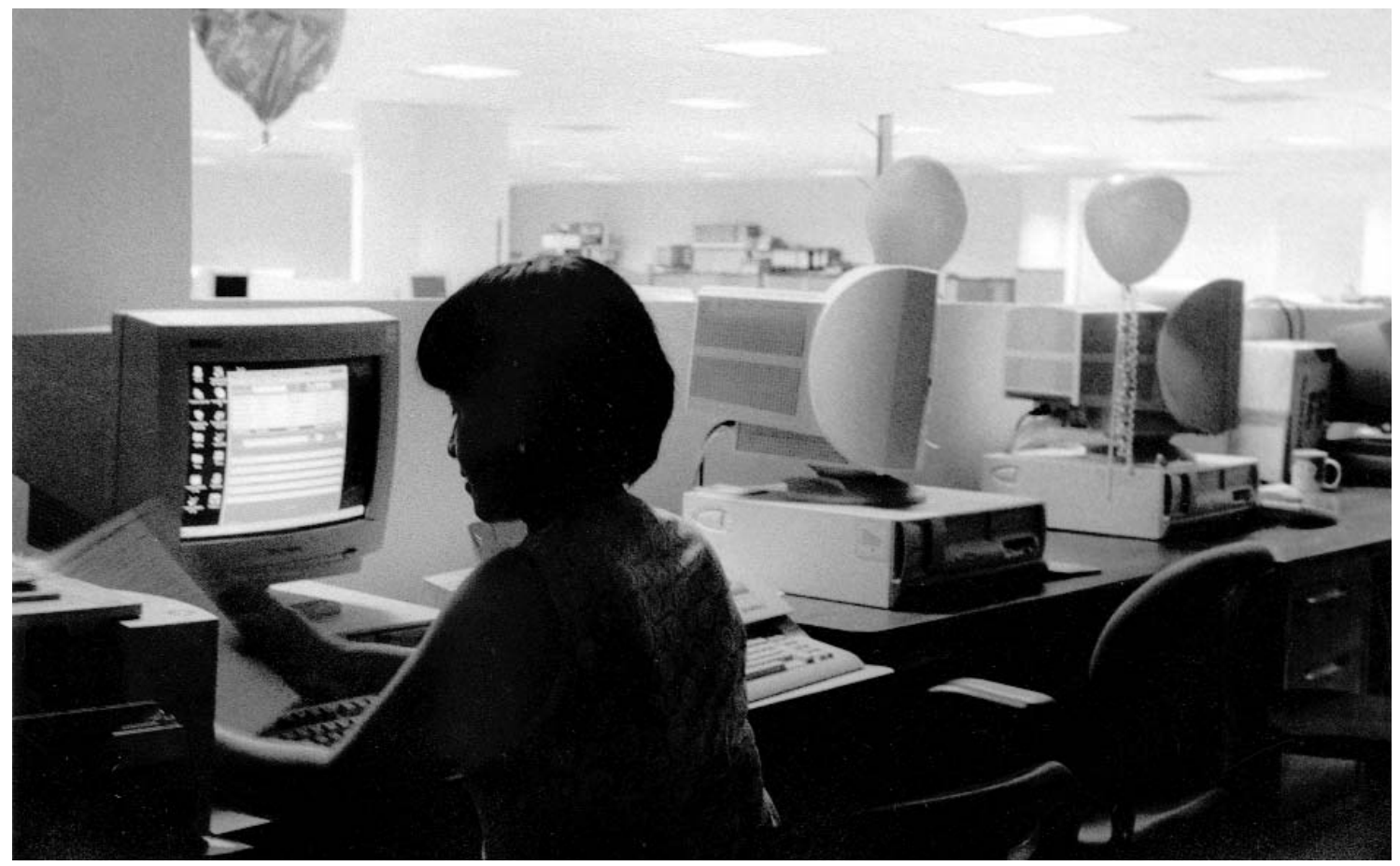

De la serie: Alto, mujeres trabajando, 2003 / Roxana Acevedo

Esta situación parece tener lugar como parte de un proceso de segregación que viven las mujeres ejecutivas, así como de las dificultades que entraña el combinar extensos horarios inflexibles de trabajo y el desempeño de su rol familiar. Aunque es necesario continuar analizando la información recopilada para establecer claramente estos puntos por ahora bosquejados.

\section{Bibliografía}

Arango Luz Gabriel, Mara Viveros y Rosa Bernal, 1995, Mujeres ejecutivas. Dilemas comunes alternativas individuales, Ediciones Uniandes, Santa Fe de Bogotá, D.C. Colombia.

Burke J. Roland y Cary L. Cooper (eds.), 2000, The Organization in Crisis: Downsizing, Restructuring and Privatization, Blackwell Publishers, Oxford.

Davidson Marilyn y Cary L. Cooper, 1992, Shattering the Glass Ceiling, Paul Shapman Publishing, Londres.

Denzin Norman, 1970, The Research Act, Aldine Press, Chicago.

Doremus Paul N., William W. Keller, Lois W. Pauly y Simon Reich, 1998, The Myth of the Global Corporation, Princeton University Press, Pinceton, Nueva Jersey.

Elder Jr. ,Glen H., 1989, “Perspectives on the Life Course”, en
Glen H. Elder Jr. (ed.), Life Course Dynamics. Trayectories end Transitions, 1968-1980, Cornell University Press, Ithaca, pp. 14-27.

Marsden David, 1999, A Theory of Employment Systems, Micro-foundations of Social Diversity, Oxford University Press, Nueva York.

Oliveira, Orlandina de y Paul Osterman (eds.), 1996, Broken Ladders, Oxford University Press, Nueva York.

Parnreiter Chirstof, 2000, "La ciudad de México en la red de ciudades globales. Resultados de un análisis y una agenda para una futura investigación", en Anuario de espacios urbanos, UAM-Azcapotzalco, pp. 189-216.

Pérez-Lizaur Marisol, 2000, "Decisiones laborales entre ejecutivas de alto nivel de una gran corporación transnacional", en Carmen Bueno (coord.), Globalización: una cuestión antropológica, CIESAS, Miguel Ángel Porrúa, México, pp. 167-190.

Sassen Saskia, 1991, Global City: New York, London, Tokio, Princeton University Press.

_ 2001, Global City: New York, London, Tokio, Princeton University Press.

Sekaran Uma y Frederick T.L. Leong (eds.), 1992, Womanpower. Managing in times of Demographic Turbulence, Sage Publications, Newbury Park, California.

Zweigenhaft Richard y G. William Domhoff, 1998, Diversity in the Power Elite. Have Women and Minorities Reached the Top?, Yale University Press, Londres. 